\title{
Genetic Testing for Familial Breast Cancer - Ethical Questions Concerning Individual Rights and Social Responsibility
}

\author{
Sigrid Graumann \\ Zentrum für Ethik in den Wissenschaften, \\ Universität Tübingen, Germany
}

The provision of genetic tests for familial breast cancer can have several problematic consequences. In the first part of my presentation I will briefly summarise the aspects which are of ethical relevance. In the second part I will develop a framework of principles for ethical evaluation. In the third part I will discuss some of the major aspects, problems and questions which are within this ethical framework.

\section{PROBLEMATIC CONSEQUENCES OF GENETIC TESTS FOR FAMILIAL BREAST CANCER}

In most respects, the problematic consequences of genetic tests for familial breast cancer are very similar to those of genetic tests for other diseases:

(1) Some concern the need to cope with the knowledge of a certain risk and not with an existing disease. How is it possible to gain an adequate understanding of what genetic risk is, particularly given the background of a popular conception of genetic determinism? Are there therapeutic options? In the case of breast cancer, one therapeutic option may be prophylactic mastectomy, which is problematic itself. Are there consequences for a person's future plans or family planning? How does the patient cope with the fear of dying? All this may cause psychological problems. Discussion of these questions needs a good empirical basis. From an ethical point of view, the central question is: Under what conditions is it justifiable to expose the patient to such psychological risks?

(2) Every genetic test which deals with inherited traits provides not only information about the patient him- or herself, but also information about relatives. This may subject such relatives to the same psychological consequences without them having been asked if they want to receive such information.

(3) There may be third parties interested in genetic data like employers and insurance companies. This may lead to discrimination against the patient. How is this conflict of interests to be dealt with?

(4) Genetic tests for familial breast cancer may be used for screening. It is difficult to guarantee the protection of the patients' autonomy in the context of screening; screening is normally done for health policy purposes. In the case of infectious diseases like tuberculosis, screening can be justified as a measure necessary for the protection of others. PKUscreening of new-borns can be justified on the grounds that it can have good and in themselves unproblematic therapeutic consequences. Genetic screening for familial breast cancer seems to be more problematic than these examples.

(5) The resources for health care services are limited. How should genetic tests be evaluated in this context? 


\section{ETHICAL FRAMEWORK}

The central aim of medical ethics is to protect the patients' wellbeing and interests in the individual physician-patient-relationship, in his or her dealings with professional health care service and with the medical institution in general.

The protection of the patients' autonomy is one of the most important principles. The patients need certain preconditions to make autonomous decisions possible like proper information and a non-authoritarian atmosphere. In case of pain and fear, however, this always remains difficult. Nevertheless, referring to patients' autonomy in the context of genetic tests means that there is a right to know and a right not to know, which has to be strictly respected.

However, to respect the patients' autonomy is essential but not enough. Considering the vulnerability of the patient, the physician's or the clinical team's aim must be to foster his wellbeing and care for him.

Any diagnostic or therapeutic intervention may lead to damage or other negative "side effects" for the patient. This can only be justified if the contribution to the patients' wellbeing outweighs any negative consequences. This means that as a general rule ...

... any diagnostic or therapeutic intervention is only morally acceptable if the patient gives his free and informed consent and if the contribution to the patients well-being is overriding all negative side effects.

This rule is of particular importance if scientific interests are involved. In this case it is also important that ...

... if a conflict between the wellbeing of the patient and scientific interests arises, the former is generally given priority.

These two rules may be understood as a very brief and basic summary of the guidelines of medical ethics as they are laid down in the Declaration of Helsinki or in the Nuremberg Code, for example.
Regarding the relevance of genetic information for relatives, the rules mentioned have to be expanded. The relatives who are affected have a right to know and not to know as well. How these rights can be protected is another question.

I have yet to address the conflicts of interest with third parties like employers and insurance companies, because this is not a question inherent to medical ethics. From a socio-ethical point of view, however, any discrimination against persons or groups in a society should be avoided.

The further socio-ethical question is whether genetic tests should be introduced into clinical practice and covered by public health-care services, taking into account the limitedness of resources. Generally the principle of social justice says that individual rights and social wellbeing have to be balanced and that social wellbeing should never undermine individual rights. In the context of health-care services this means that they should meet the basic health care needs for everyone and the specific need for severely and chronically ill persons - or in other words: everyone should get what he or she really needs and some persons need more than others.

\section{EVALUATION}

I come to my last point, to the ethical evaluation of genetic tests for familial breast cancer.

(1) The right to know and right not to know should be respected in any case. Because of the difficulties involved with autonomous decisions of patients and the possibility of negative consequences, good counselling should be the prerequisite for all genetic tests for breast cancer. The counselling should facilitate genuinely autonomous decisions; all possible good and bad consequences, not only medical ones, should be mentioned. I would like to emphasize that from an ethical point of view, such counselling is not only one option but a prerequisite for the justification of genetic services.

(2) Furthermore, the problem concerning information about relatives should be addressed 
by the counsellors. Nevertheless, genetic tests will always contradict the autonomy of afflicted relatives. This is a dilemma we cannot escape.

(3) From an ethical point of view, screening may be more problematic than it is useful. In my view, the advantages are not so great as to outweigh the problem of protecting patients' rights and in particular patients' autonomy in this context.

(4) The prevention of discrimination for genetic reasons should be guaranteed by legislation before introducing genetic services into clinical practice. If a certain test is available e.g. for breast cancer it is difficult to prevent its use by employers and insurance companies in the long run as long as they are allowed to ask for other medical data on their clients. Therefore legislation must protect the privacy of the patient against the interests of employers and insurance companies - and that means changing the actual practice in many countries.

(5) From the social justice perspective, providing genetic tests for breast cancer in the framework of health-care services seems to be problematic in so far as such services may use more resources than they save in the long run. And it is difficult to decide if they are so beneficial that their use on patients is justifiable in the name of solidarity. 


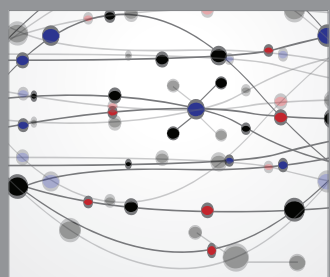

The Scientific World Journal
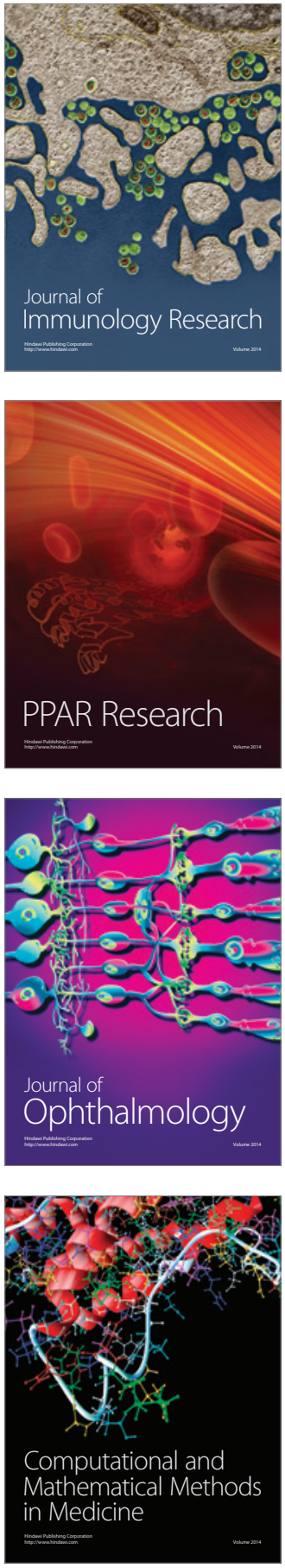

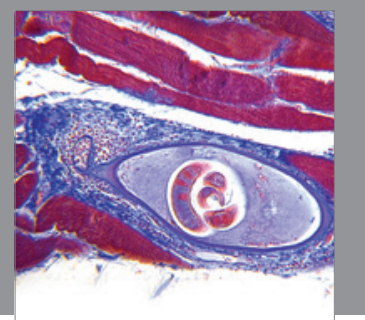

Gastroenterology

Research and Practice
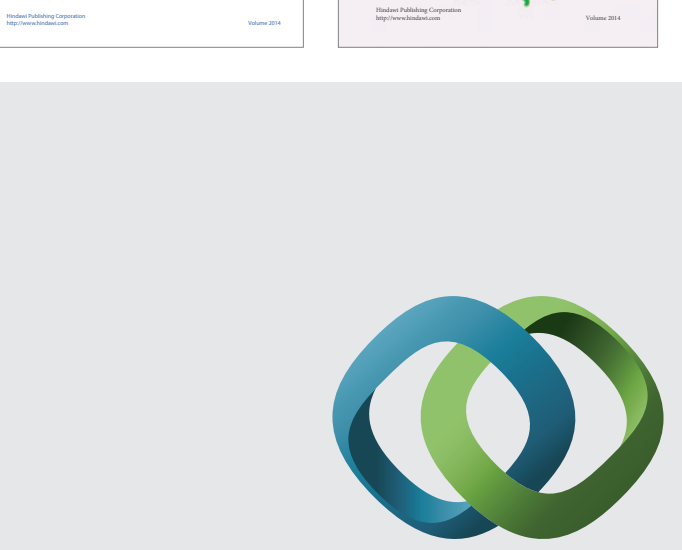

\section{Hindawi}

Submit your manuscripts at

http://www.hindawi.com
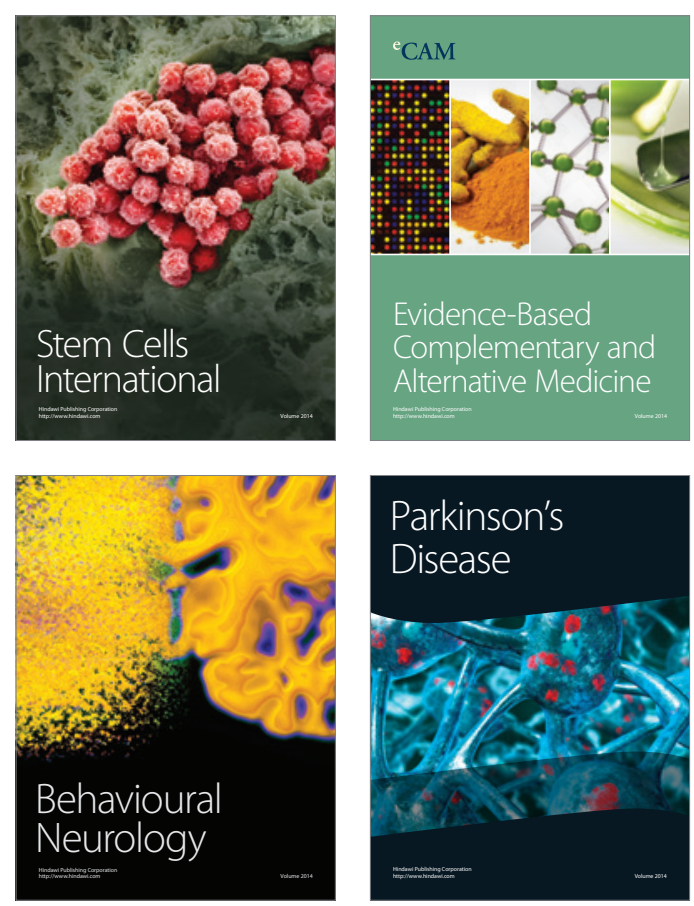

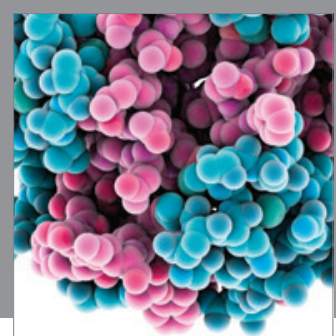

Journal of
Diabetes Research

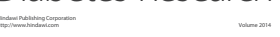

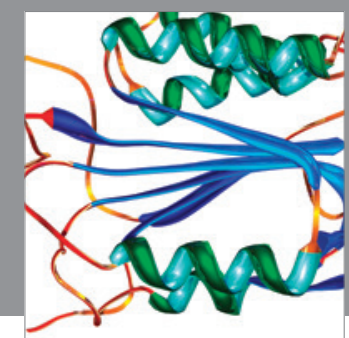

Disease Markers
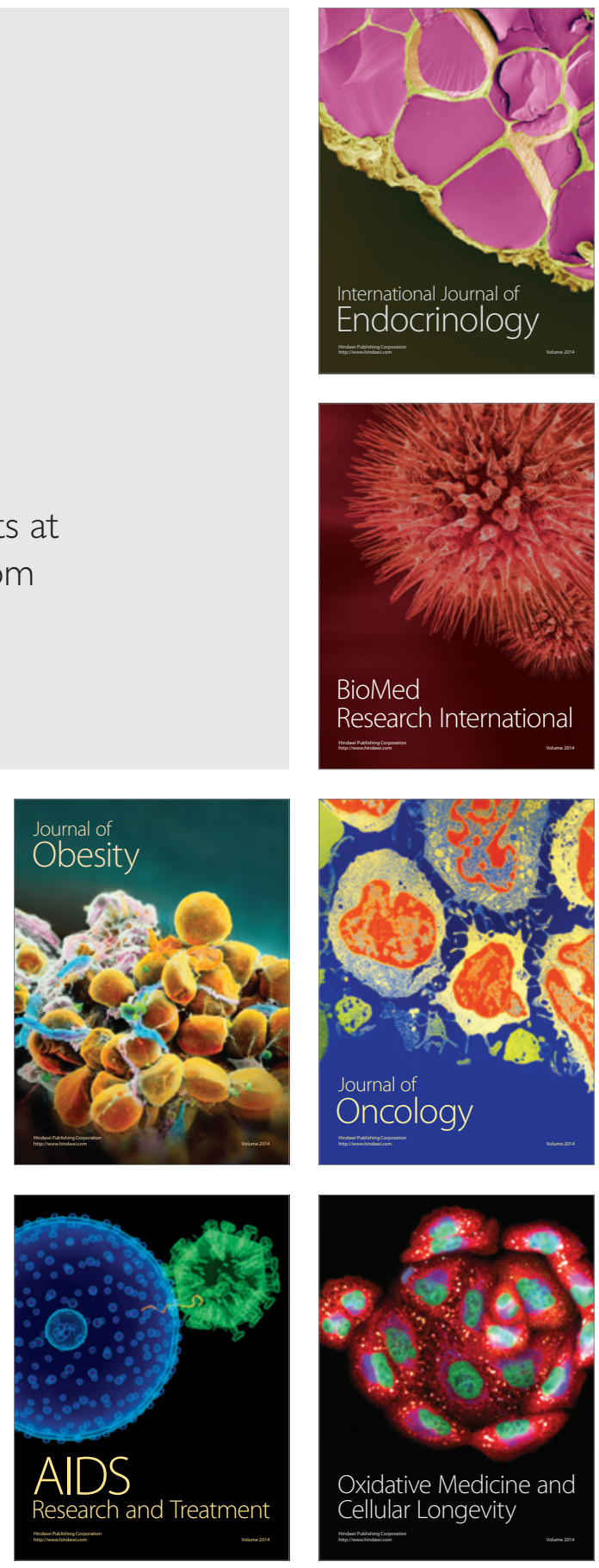